\title{
DOPO-Modified Cellulose Microsphere: Preparation and Application for Selective Adsorption U(VI) under Acidic Solutions
}

\section{Di Wen}

Huazhong University of Science and Technology

\section{Cong Xie}

Hubei University Of Science and Technology

Manman Zhang

Huazhong University of Science and Technology

Zhen Dong

Huazhong University of Science and Technology

\section{Maolin Zhai}

Peking University

Long Zhao ( $\nabla$ ryuuchou@hotmail.com )

Huazhong University of Science and Technology https://orcid.org/0000-0002-6126-2210

\section{Research Article}

Keywords: Cellulose, DOPO, U(VI), Adsorption, Chelation

Posted Date: November 9th, 2021

DOI: https://doi.org/10.21203/rs.3.rs-1035340/v1

License: (c) (i) This work is licensed under a Creative Commons Attribution 4.0 International License.

Read Full License 


\section{U(VI) under acidic solutions}

Di Wen ${ }^{1,2} \uparrow$, Cong Xie ${ }^{3} \dagger$, Manman Zhang ${ }^{1,2}$, Zhen Dong ${ }^{1}$, Maolin Zhai ${ }^{4}$, Long Zhao ${ }^{1 *}$

41 State Key Laboratory of Advanced Electromagnetic Engineering and Technology, School of Electrical

5 and Electronic Engineering, Huazhong University of Science and Technology, Wuhan 430074, China

62 School of Chemistry and Chemical Engineering, Huazhong University of Science and Technology,

7 Wuhan 430074 , China

83 Non-power Nuclear Technology Research and Development Center, Hubei University of Science and

9 Technology, Xianning 437100, China

104 Beijing National Laboratory for Molecular Sciences, Radiochemistry and Radiation Chemistry Key

11 Laboratory of Fundamental Science, Key Laboratory of Polymer Chemistry and Physics of the Ministry

12 of Education, College of Chemistry and Molecular Engineering, Peking University, Beijing 100871,

13 China

14

15

16

17

18

19

$\dagger$ refer to equal contribution

Corresponding author.

E-mail addresses: ryuuchou@hotmail.com (Long Zhao), zhaolong@hust.edu.cn (Long Zhao) 
Effective radioactive wastewater disposal is of great significance to the wide use of nuclear energy. dimethyneimino)] diphenol (t-DOPO) was used to modify microcrystalline cellulose microsphere (tDOPOR) to further enhance it affinity toward $\mathrm{U}(\mathrm{VI})$ through radiation method. The t-DOPOR were characterized for structural, morphological, and thermal properties by FTIR, SEM and TGA, which prove that t-DOPO is successfully modified on cellulose. Combination the advantage of cellulose and t-DOPO, t-DOPOR possessed abundant functional group ( $-\mathrm{OH},-\mathrm{NH}$ and $\mathrm{P}=\mathrm{O})$, and exhibited extremely strong affinity toward U(VI) with a maximum adsorption capacity of $51.51 \mathrm{mg} / \mathrm{g}$ at $\mathrm{pH} 3$. Particularly, A large distribution, $\mathrm{K}_{\mathrm{d}}^{\mathrm{U}}$, up to $2.54 \times 10^{4} \mathrm{~mL} \mathrm{~g}^{-1}$ is found, implying extremely strong affinity toward $\mathrm{U}(\mathrm{VI})$ than $\mathrm{Ln}(\mathrm{III})(\mathrm{La}(\mathrm{III}), \mathrm{Eu}(\mathrm{III}), \mathrm{Dy}(\mathrm{III}), \mathrm{Yb}(\mathrm{III}))$ at the binary system. Dynamic column experiment confirmed that t-DOPOR could separate selectively U(VI) in column experiment. In addition, even in the simulated groundwater trace amount of $\mathrm{U}(\mathrm{VI})$ was also eliminated efficiently by t-DOPOR. Lastly, the adsorption mechanism elaborated by XPS analysis was inner-sphere surface complexation between U(VI) and -OH, -NH and $\mathrm{P}=\mathrm{O}$ groups of $\mathrm{t}-\mathrm{DOPOR}$. Overall, the synthesized t-DOPOR may be utilized as a promising adsorbent for separation and remediation of U(VI) from wastewater.

Keywords: Cellulose; DOPO; U(VI); Adsorption; Chelation

Statements and Declarations

Author contributions on previous versions of the manuscript. All authors read and approved the final manuscript. Conflicts of Interest 


\section{Introduction}

With the development of nuclear technology, an increasing number of radioactive wastes have been released into the environment (Ding et al. 2015). Uranium, a major resource of nuclear fuel, is inevitably discharged with the release of radioactive wastes, which can pose serious health risks to human beings due to its biological toxicity and high radioactivity (Yuan et al. 2017). Therefore, from the standpoints of environmental protection, it is crucial to eliminate the uranium from wastewater.

Various techniques, such as ion exchange, liquid-liquid extraction, chemical precipitation, filtration, and adsorption, (Mellah et al. 2007; Beltrami et al. 2014; Shao et al. 2018; Satilmis et al. 2019) have been used to remove $\mathrm{U}(\mathrm{VI})$. Of the adopted methods, adsorption has considered as one of the more efficient methods due to its high removal efficiency, low cost, and simple operation on a large scale (Cheng et al. 2016). Recently, natural biomaterials are considered as a kind of useful matrix due to their cost-effectiveness, biodegradability, environ-mentally friendly, controllability (Cao et al. 2017). Among various natural bio-based materials, microcrystalline cellulose microsphere (MCC), possessing a highly crystalline structure, has attracted wide attention due to its unique mechanical and chemical properties (Hokkanen et al. 2016; Dong and Zhao 2018). In our previous work, it is evident that MCC can be used as a matrix to synthesize functionalized adsorbents and the prepared adsorbents with the spherical threedimensional structure was favorable for the application of fixed-bed column and possessed good recyclability (Dong and Zhao 2018). However, the low adsorption capacity of MCC limited the wide application in the field of adsorption. To improve the adsorptive property of MCC, a suitable monomer with special functional group is necessary.

On the basis of Lewis acid-base theory, there are electrostatic interaction or/and chelation between the U(VI) (Lewis acids) and phosphate groups (Lewis base). Thus, the introduction of phosphate groups in cellulose is conducive to increase more active sites for $\mathrm{U}(\mathrm{VI})$ complexation, making it a potential solution for water treatment. After extensive investigations, various phosphorylating agents, for instance, tri-n-butylphosphate (TBP) (Zheng et al. 2018), di-1-methyl heptyl methyl phosphonate (DMHMP) (Li et al. 2017), organic phosphine (Wang et al. 2019; Yuan et al. 2020; Zhang et al. 2020) have been used to prepare phosphate-based adsorbents, which showed excellent ability in chelating metals.

Notably, 9, 10-dihydro-9-oxa-10-phosphaphenanthrene-10-oxide (DOPO) is a type of cyclic 
phosphate with a diphenyl structure, which have received increasing attention owing to their high reactivity, good thermal properties (Bai et al. 2013; Wendels et al. 2017). In addition, DOPO contains phosphorus-bearing groups such as $\mathrm{P}=\mathrm{O}, \mathrm{P}-\mathrm{O}$, possessing a strong chelation ability toward $\mathrm{U}(\mathrm{VI})$ (Budnyak et al. 2016; Pan et al. 2019). Therefore, DOPO could be considered as a phosphorus-bearing monomer, and then grafted onto the solid matrix to capturing $\mathrm{U}(\mathrm{VI})$. To the best of our knowledge, few efforts are devoted to investigating material modified by DOPO and DOPO derivative for the adsorption of U(VI).

In the current work, 4, 4' -[1, 4-phenyl-bis (9, 10-dihydro-9-oxa-10-phosphaphenanthrene-10-yl) dimethyneimino)] diphenol (t-DOPO) (Xie et al. 2018) was selected as functionalized monomer to enhance MCC affinity toward U(VI), owing to it not only has phosphorus-bearing groups, but also contains other functional groups such as $-\mathrm{OH}$, $-\mathrm{NH}$, which also shown a strong affinity toward $\mathrm{U}(\mathrm{VI})$ (Ai et al. 2018; Huang et al. 2018). Combination the advantage of cellulose and t-DOPO, t-DOPOR with high mechanical strength, chemical stability and rich functional group is expected to show synergistic effect for U(VI) removal. Therefore, a novel t-DOPO modified cellulose microspheres (t-DOPOR) was fabricated by radiation technique and used as an adsorbent for removal of $\mathrm{U}(\mathrm{VI})$ under acidic solutions. The structural, morphological, and thermal properties of t-DOPOR was investigated through various characteristic methods like FTIR, SEM and TGA, and the adsorption performance of t-DOPOR toward $\mathrm{U}(\mathrm{VI})$ were systematically investigated under different environmental factors (solution $\mathrm{pH}$, contact time, ionic strength, competitive metal ions, and so on). In addition, the investigation of dynamic column experiment from simulated radioactive wastewater and the removal of the trace amount of $\mathrm{U}(\mathrm{VI})$ from contaminated groundwater was also carried out. The adsorption mechanism of U(VI) on t-DOPOR was highlighted by XPS. This work is expected to look for a powerful and high selective adsorbent for removal of $\mathrm{U}(\mathrm{VI})$ from radioactive wastewater.

\section{Material and Experiments}

Materials

Microcrystalline cellulose microspheres (MCC) (average particle size ca. $220 \mu \mathrm{m}$ ) were supplied by Asahi Kasei Chemicals Corporation (Japan). Glycidyl Methacrylate (GMA), methanol, 
112 dimethylformamide (DMF), and dimethylsulfoxide (DMSO) were purchased from Sinopharm Chemical

113 Reagent, China. $\mathrm{UO}_{2}\left(\mathrm{NO}_{3}\right)_{2} 6 \mathrm{H}_{2} \mathrm{O}, \mathrm{KReO}_{4}, \mathrm{La}\left(\mathrm{NO}_{3}\right)_{3} \quad 6 \mathrm{H}_{2} \mathrm{O}, \mathrm{Ce}\left(\mathrm{NO}_{3}\right)_{3} 6 \mathrm{H}_{2} \mathrm{O}, \mathrm{Co}\left(\mathrm{NO}_{3}\right)_{2} 6 \mathrm{H}_{2} \mathrm{O}$,

$114 \mathrm{Nd}\left(\mathrm{NO}_{3}\right)_{3} 6 \mathrm{H}_{2} \mathrm{O}, \mathrm{Dy}\left(\mathrm{NO}_{3}\right)_{3} 6 \mathrm{H}_{2} \mathrm{O}$, and $\mathrm{Yb}\left(\mathrm{NO}_{3}\right)_{3} 6 \mathrm{H}_{2} \mathrm{O}$ were received from Merck (Germany). $\mathrm{ZnCl}_{2}$,

$115 \mathrm{NiCl}_{2} 6 \mathrm{H}_{2} \mathrm{O}, \mathrm{HNO}$, and $\mathrm{HCl}$ were purchased from Sinopharm (China). All reagents were of analytical-

116 grade and directly used.

118 Synthesis of the t-DOPOR

119 The synthetic route of modified cellulose microsphere adsorbent (t-DOPOR) is illustrated in scheme

120 1. Firstly, GMA was grafted onto GMA to prepare MCC-g-GMA through radiation induced graft

121 copolymerization as reported in previous work (Dong and Zhao 2018). Secondly, certain amounts of 4,

122 4'- [1, 4-phenyl-bis (9, 10-dihydro-9-oxa-10-phosphaphenanthrene-10-yl) dimethyneimino)] diphenol

123 (t-DOPO) and 30\% NaOH aqueous solution were added into DMF solution. And then the MCC-g-GMA

124 was immersed in these solutions, which equilibrated at $80{ }^{\circ} \mathrm{C}$ for several hours. After that, the final

125 product obtained was purified using deionized water. By drying in an oven at $60{ }^{\circ} \mathrm{C}, \mathrm{t}$-DOPO

126 functionalized microcrystalline cellulose microspheres (t-DOPOR) was obtained.

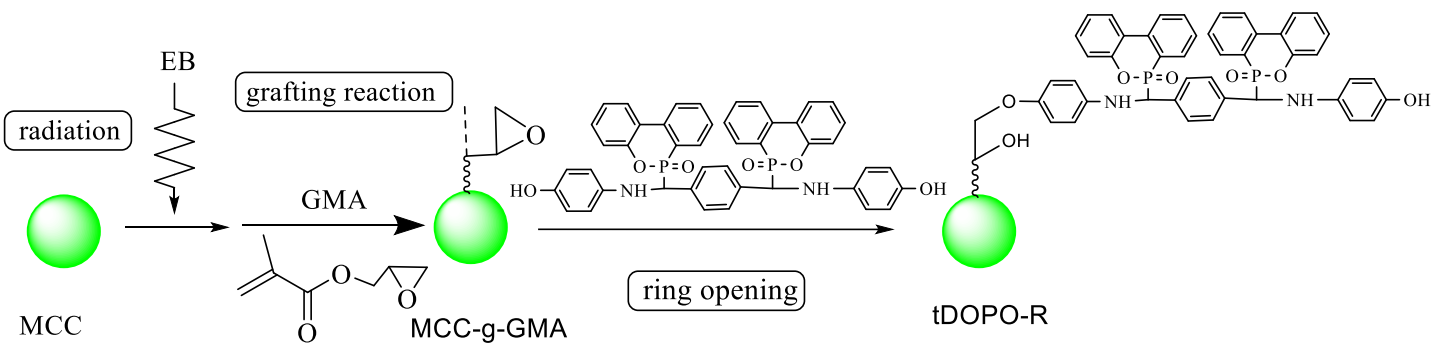

Scheme 1 synthetic route of t-DOPOR via radiation grafting of GMA and ring opening

Characterization

The prepared t-DOPOR was characterized by FT-IR (Nicolet AVATAR 320 FT-IR

132 spectrophotometer), TG (TGA55, TA Instruments, USA), and XPS (AXIS-UItra instrument from Kratos

133 Analytical). The FTIR spectra with the wavelength range ranging from $4000-400 \mathrm{~cm}^{-1}$ was recorded.

134 The TG analysis was performed within $0-800{ }^{\circ} \mathrm{C}$ at a heating rate of $10{ }^{\circ} \mathrm{C} / \mathrm{min}$ under air atmosphere.

135 The XPS was conducted by using monochromatic Al Ka radiation and low energy electron flooding for

136 charge compensation. The zero potentials of t-DOPOR in the $\mathrm{pH}$ range of 1.0-12.0 were measured by 
Batch adsorption experiments

The batch experiments of U(VI) removal were carried out with $0.01 \mathrm{~g}$ t-DOPOR adding into $10 \mathrm{~mL}$

141 polyethylene tubes at $313 \mathrm{~K}$. That is, the ratio of solid (adsorbent dosage) and liquid (solution Volume)

$142(\mathrm{~m} / \mathrm{v})$ was $1 \mathrm{~L} \cdot \mathrm{g}^{-1}$. The $\mathrm{pH}$ of the testing solution was adjusted by $0.1 \mathrm{M} \mathrm{HCl}$ or $\mathrm{NaOH}$. After a certain

143 time $(\mathrm{t})$, the solutions were collected by filtered with a syringe filter $(0.45 \mu \mathrm{m})$.

144 The adsorption amount of U(VI) $\left(\mathrm{q}_{\mathrm{e}}, \mathrm{mg} / \mathrm{g}\right)$ and removal efficiency (E, \%) by t-DOPOR were 145 calculated by the initial $\left(\mathrm{C}_{\mathrm{o}}, \mathrm{mg} / \mathrm{L}\right)$ and equilibrium concentration of $\mathrm{U}(\mathrm{VI})(\mathrm{Ce}, \mathrm{mg} / \mathrm{L})$ as following Eq. $146 \quad(1-3)$ : $(1-3)$ :

Where $\mathrm{V}$ and $\mathrm{m}$ was the volume of $\mathrm{U}(\mathrm{VI})$ solution and the weight of t-DOPOR, respectively.

151 by Eq. (3-4):

Where $\mathrm{K}_{\mathrm{d}(\mathrm{U})}$ and $\mathrm{K}_{\mathrm{d}(\mathrm{M})}$ represented the distribution coefficient of $\mathrm{U}(\mathrm{VI})$ and other representative lanthanides ions (La(III), Eu(III), Dy(III), and $\mathrm{Yb}(\mathrm{III}))$. The concentration of metal ions was measured by Inductively Coupled Plasma Optical Emission Spectrometer (ICP-OES-5110, Agilent, American) and Inductively Coupled Plasma Mass Spectrometry (ICP-MS, 147 PE, USA). The ICP data were the average of three parallel measurement.

To further explore the feasibility of t-DOPOR toward $\mathrm{U}(\mathrm{VI})$ in practical application, column 162 adsorption experiments were performed in plastic column $(\varphi 5 \times 60 \mathrm{~mm})$, and the column was filled with 163 t-DOPOR (0.4 g). Simulated radioactive wastewater containing (U(VI), La(III), Co(II), Ni(II), Zn(II)and 
$164 \mathrm{Nd}(\mathrm{III})$ ) was prepared and used as feed solution. The velocity of space (SV) was regulated at $19.32 \mathrm{~h}^{-1}$.

165 The effluent sample was collected at regular intervals and analyzed for metal ions using ICP.

$167 \mathrm{U}(\mathrm{VI})$ uptake at trace amount of concentration

168 The contaminated pure water was prepared by injecting U(VI) into pure water. The composition of 169 simulated groundwater (Chen et al. 2019) includes $0.32 \mathrm{mM} \mathrm{NaNO}_{3}, 0.78 \mathrm{mM} \mathrm{Na}_{2} \mathrm{SO}_{4}, 0.054 \mathrm{mM} \mathrm{K}_{2} \mathrm{SO}_{4}$, $1700.41 \mathrm{mM} \mathrm{MgSO}_{4}, 0.17 \mathrm{mM} \mathrm{NaHCO}_{3}$, and the uranium concentration was $24.3 \mathrm{ug} / \mathrm{L}$. The simulated 171 groundwater was used. $0.01 \mathrm{~g}$ t-DOPOR were added into $10 \mathrm{~mL}$ of contaminated pure water (6.37 ppb), 172 simulated groundwater (24.3 ppb). After shaking for $48 \mathrm{~h}$ in $313 \mathrm{~K}$, the residual trace amount of U(VI) 173 was detected by ICP-MS.

\section{Results and discussion}

176 Characterization

$177 \quad$ FTIR and SEM analysis

178 The conversion rate of t-DOPO introduced into cellulose was calculated to be $30 \%$ in term of weight 179 method. The FTIR spectra of MCC, MCC-g-GMA, t-DOPOR are given in Fig. 1a. It's seen that after the 180 ring-opening reaction, the peak of the epoxy group $\left(\sim 904 \mathrm{~cm}^{-1}, \sim 843 \mathrm{~cm}^{-1}\right)$ disappeared significantly. By 181 contrast, the new adsorption peak of $\mathrm{P}=\mathrm{O}\left(\sim 1243 \mathrm{~cm}^{-1}\right)($ Chen et al. 2012$), \mathrm{P}-\mathrm{O}-\mathrm{C}\left(\sim 1115 \mathrm{~cm}^{-1}, 888 \mathrm{~cm}^{-}\right.$ $182^{1}$ ) (Yuan et al. 2020) were appeared in t-DOPOR. Also, the appearance of new peak at $2922 \mathrm{~cm}^{-1}, 2851$ $183 \mathrm{~cm}^{-1}$ could be ascribed to $=\mathrm{CH}$ and $-\mathrm{CH}$ stretching of benzene ring (Guo et al. 2019). The band at $\sim 3425$ $184 \mathrm{~cm}^{-1}$ are assigned to $-\mathrm{NH}$ overlapping with the stretching vibration of the $-\mathrm{OH}$ group (Zhu et al. 185 2018).Thus, the above results proved that the successful introduction of t-DOPO to the microcrystalline 186 cellulose microsphere (MCC)..

187 Fig. 1b-d showed the SEM images of MCC, MCC-GMA and t-DOPOR. MGG exhibited a spherical 188 shape with smooth surface, while the surfaces of MCC-GMA and t-DOPOR appear rougher with some 189 fracture surfaces. Among the sample, t-DOPOR exhibited largest spherical shape with a diameter ranging 190 from 150-200 $\mu \mathrm{m}$. These changes were attributed to addition of functional groups (confirmed by FTIR), 191 which directly affected the surface morphology of t-DOPOR. 

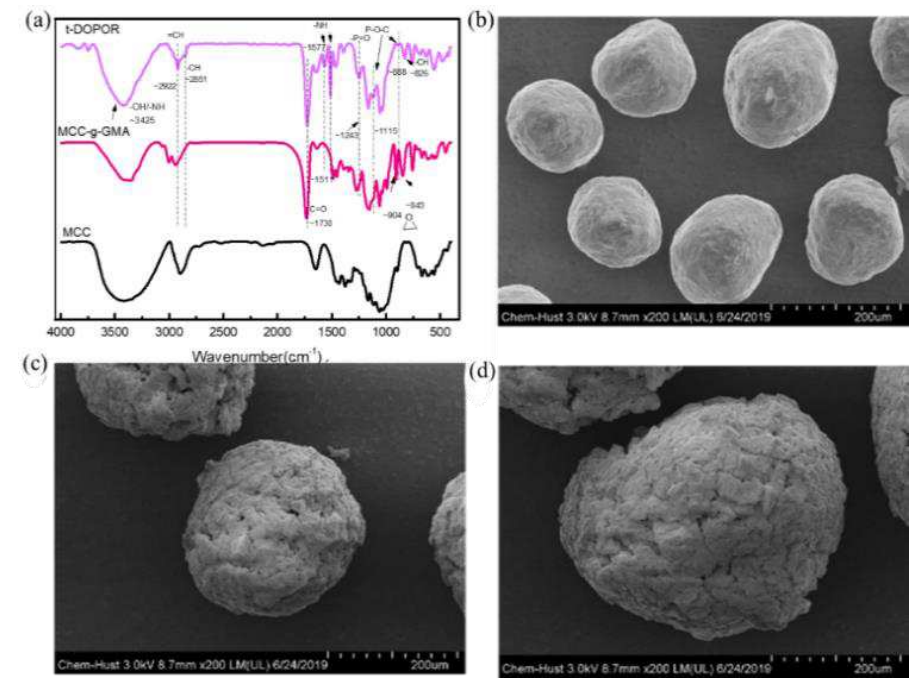

Fig. 1 FTIR spectra of MCC, MCC-g-GMA, t-DOPOR (a), SEM mages of MCC (b), MCC-GMA

(c) and t-DOPOR (d)

TG analysis

The excellent thermal stability of adsorbent is important from the view of practical application. The thermos-stability of MCC, MCC-g-GMA, t-DOPOR was evaluated by TG analysis. The results of TG curves and DTGA (Derivative thermogravimetric analysis) were exhibits as Fig. 2, the thermal stability of t-DOPOR was improved in compared with MCC. As shown in Fig. 2(a), the three peak were represent as volatilization of physically adsorbed water, pyrolysis of the grafted GMA and MCC, and the grafted 202 phosphorus-containing t-DOPO, respectively (Misra et al. 2016). t-DOPOR exhibited higher char yields 203 (22.77\%) than MCC and MCC-g-GMA at $800{ }^{\circ} \mathrm{C}$ due to the introduction to phosphorus-containing 204 groups of t-DOPO. The TG curve of t-DOPOR indicated three distinct stages corresponding to the three peaks in the DTGA curve (as shown in Fig. 2(b)). Generally, the temperature of radioactive wastewater

206 would elevate with the fission of radionuclides therein (Cai et al. 2017). Thus, the great thermal stability 207 of the t-DOPOR is conducive to the remediation of radionuclide effluents. 

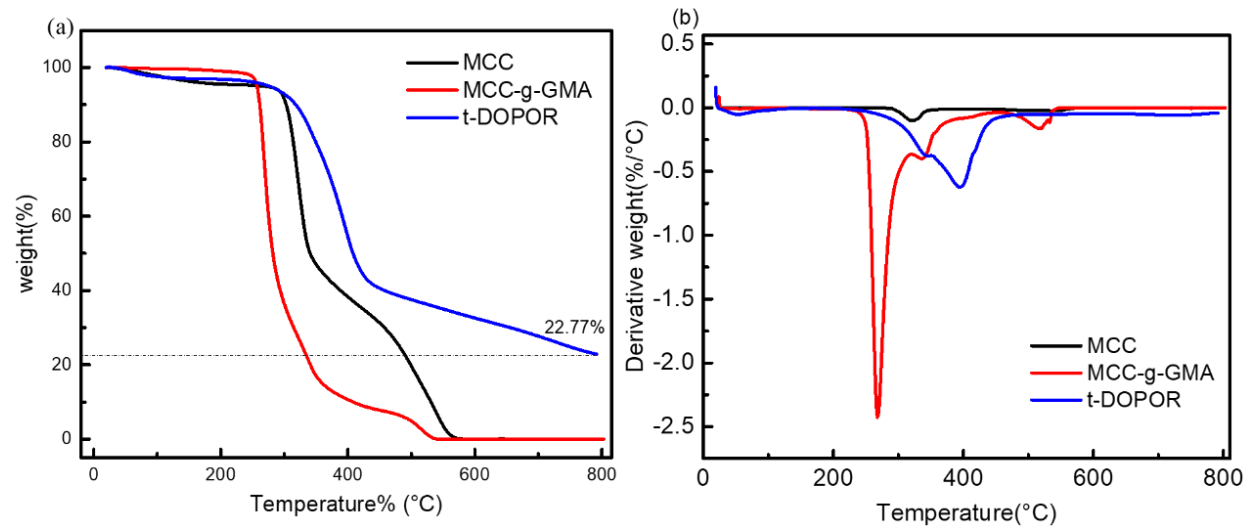

Fig. 2 TGA (a) and the corresponding differential thermal gravimetric analysis (DTG) (b) curves of

$\mathrm{pH}$ studies

Solution $\mathrm{pH}$ is an important parameter that affects both adsorbent surfaces and uranium species. In

214 view of this, the adsorption efficiency of $\mathrm{U}(\mathrm{VI})$ by t-DOPOR was investigated at $\mathrm{pH}$ ranging from 1 to

215 10. As shown in Fig. 3a, the adsorption efficiency of $\mathrm{U}(\mathrm{VI})$ increased dramatically from $12.7 \mathrm{mg} / \mathrm{g}$ to a

216 maximum value of $20.18 \mathrm{mg} / \mathrm{g}$ with the solution $\mathrm{pH}$ increased from 1 to 3 . Afterward, the adsorption

217 efficiency gradually decreased with the increasing $\mathrm{pH}$, while maintained stable at $\sim 11 \mathrm{mg} / \mathrm{g}$ as the $\mathrm{pH}$

218 ranging from 4.5-10.0. To explain the segmented sorption behavior, $\mathrm{pH}_{\mathrm{pzc}}$ analysis of t-DOPOR was

219 determined as shown in Fig. S1, which revealed the surface charge of t-DOPOR is positive at $\mathrm{pH}<7$

220 (pHpzc). The predominant species of $\mathrm{U}(\mathrm{VI})$ at solution $\mathrm{pH}<5$ (as shown in Fig. S2), namely $\mathrm{UO}_{2}{ }^{2+}$, are

221 hardly attached to the positively charged t-DOPOR surfaces due to electrostatic repulsion. The maximum

222 adsorption efficiency of t-DOPOR toward $\mathrm{U}(\mathrm{VI})$ was found at $\mathrm{pH}=3$, which indicated that the adsorption

223 of $\mathrm{U}(\mathrm{VI})$ onto t-DOPOR was attributed to surface complexation. The chelating groups such as amino,

224 hydroxyl, and phosphate shown various formation at a series of $\mathrm{pH}$ due to their protonation or 225 deprotonation behavior (Chang and Chen 2006; Dartiguelongue et al. 2016). At low pH values, the 226 hydroxyl, phosphate, and amino group on t-DOPOR will be highly protonated, thus the affinity of t227 DOPOR towards U(VI) decreases and correspondingly affect the U(VI) adsorption efficiency. With the 228 increasing $\mathrm{pH}$, the chelation groups become more deprotonated, which exposes more lone pair electrons, 229 thus increase the complexation ability of t-DOPOR toward $\mathrm{U}(\mathrm{VI})$. However, $\mathrm{UO}_{2}(\mathrm{OH})_{2}{ }^{-}, \mathrm{UO}_{2}(\mathrm{OH})_{5}{ }^{-}$, $230(\mathrm{UO} 2)_{3}(\mathrm{OH})_{7}{ }^{-}$is the main species at $\mathrm{pH}>4.5$ (Fig. S3). These huge molecules hardly approach to the 

media.
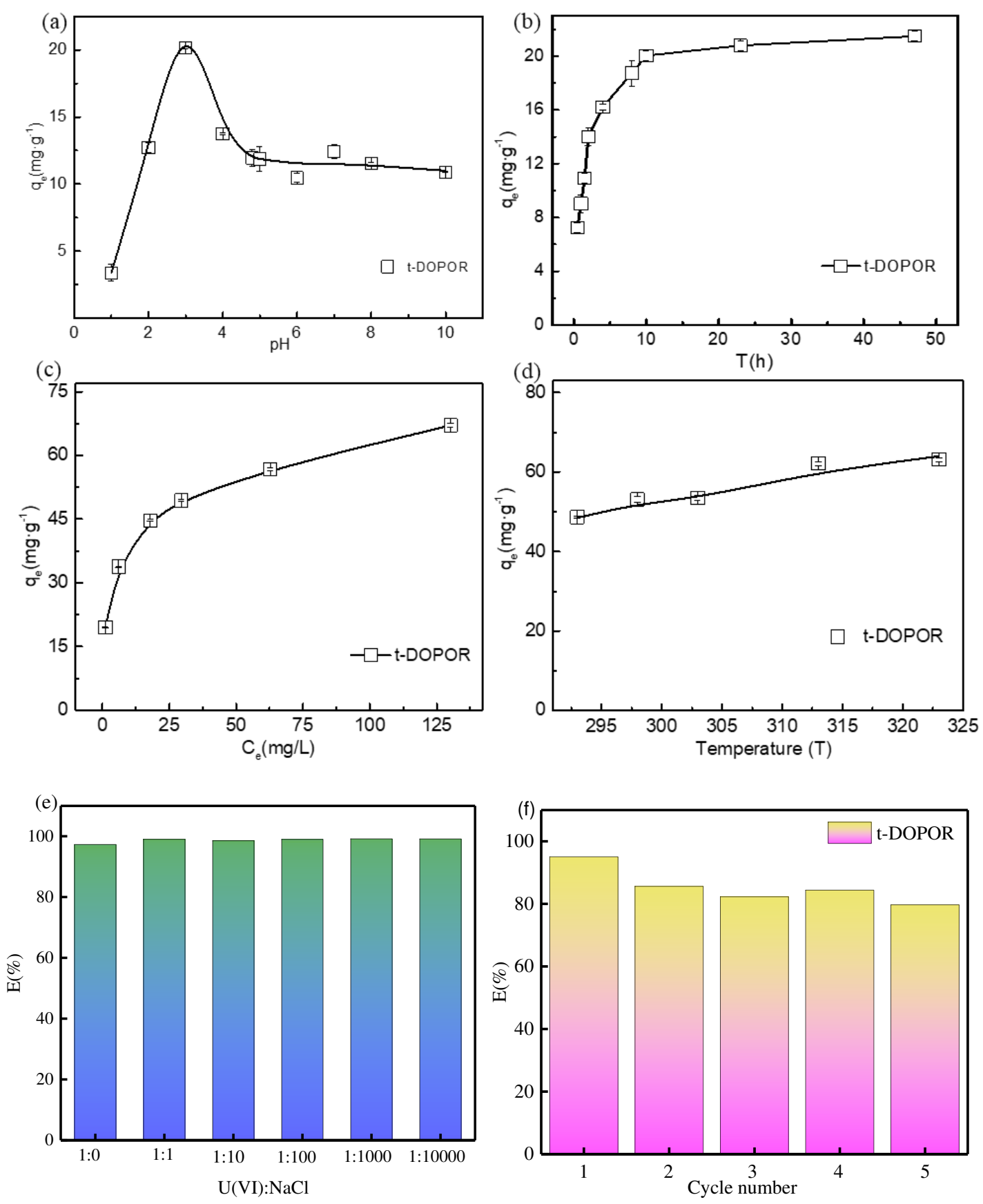

Fig. 3 (a) Effect of $p H$ on $U(V I)$ sorption $\left(m / V=1 \mathrm{~g} / \mathrm{L}, \mathrm{C}_{0(\mathrm{U}(\mathrm{VI})}=20 \mathrm{mg} / \mathrm{L}, \mathrm{t}=24 \mathrm{~h}\right)$; (b) The effect of contact time on $\mathrm{U}(\mathrm{VI})$ sorption $\left(\mathrm{m} / \mathrm{v}=1 \mathrm{~g} / \mathrm{L} \cdot \mathrm{pH}=3, \mathrm{C}_{0(\mathrm{U}(\mathrm{VI}))}=20 \mathrm{mg} / \mathrm{L}\right)$; (c) Effect of the initial $\mathrm{U}(\mathrm{VI})$ concentration $(\mathrm{m} / \mathrm{v}=1 \mathrm{~g} / \mathrm{L} \cdot \mathrm{pH}=3)$; (d) The effect of temperature; (e) the effect of ionic strength $(\mathrm{m} / \mathrm{v}=1$ $\mathrm{g} / \mathrm{L} \cdot \mathrm{pH}=3, \mathrm{C}_{0(\mathrm{U}(\mathrm{VI}))}=0.1 \mathrm{mmol} / \mathrm{L}$ ); (f) adsorptive capacity on t-DOPOR as function of the consecutive adsorption-desorption cycles $\left(\mathrm{C}_{\mathrm{OU}(\mathrm{VI})}=20 \mathrm{mg} / \mathrm{L}, \mathrm{m} / \mathrm{v}=1 \mathrm{~g} / \mathrm{L}\right)$ 
The effect of the contact time on t-DOPOR toward adsorption $\mathrm{U}(\mathrm{VI})$ at $\mathrm{pH} 5.0$ is depicted in Fig. 3b. The adsorption efficiency of $\mathrm{U}(\mathrm{VI})$ increased rapidly at $6 \mathrm{~h}$ and then gradually reached the maximum

244 at $10 \mathrm{~h}$. To investigate the controlling mechanism of the adsorption process, pseudo-first-order and 245 pseudo-second-order were used to evaluate the experimental data. As shown in table S1, the highest correlation coefficient value $\left(\mathrm{R}^{2}>0.999\right)$ of pseudo-second-order model and the closest $\mathrm{q}_{\mathrm{e}}$, cal to $\mathrm{q}_{e}$, exp indicated the adsorption kinetic data of $\mathrm{U}(\mathrm{VI})$ on t-DOPOR was well fitted by the pseudo-second-order

248 kinetics model, indicating the occurrence of chemisorption in the adsorption process.

Sorption isotherm

Adsorption isotherms are crucial to evaluate the amount of U(VI) adsorbed by adsorbents and the adsorption behavior. The adsorption isotherms were investigated using different initial concentrations of U(VI) from $20 \mathrm{mg} / \mathrm{L}$ to $200 \mathrm{mg} / \mathrm{L}$. As shown in Fig.3c, the adsorption capacity increased with the uranium concentration. To evaluate the adsorption behavior of t-DOPOR, Langmuir and Freundlich models were applied to fit the experimental data (Lv et al. 2018), the corresponding parameters were summarized in Table S2. The correlation coefficient $\left(\mathrm{R}^{2}=0.99\right)$ of the Langmuir model was larger than that of the Freundlich models $\left(\mathrm{R}^{2}=0.98\right)$. Furthermore, the maximum adsorption capacity based on the Langmuir model was calculated as $69.49 \mathrm{mg} / \mathrm{g}$, which agrees with the experimental adsorption data. The results indicated that the Langmuir model described the adsorption well, suggesting the adsorption of U(VI) on $\mathrm{t}$-DOPOR is monolayer coverage.

\section{Thermodynamic studies}

The thermodynamic parameters are conductive to evaluate the ease of the adsorption process (Xiao et al. 2019). Fig. 3d showed that the adsorption capacity of t-DOPOR toward U(VI) was increased with

265 the increasing of temperature. Based on the temperature-dependent sorption data, the thermodynamic 266 parameters (i.e., the changes of Gibbs free energy $(\triangle \mathrm{G})$, enthalpy $(\triangle \mathrm{H})$ and entropy $(\triangle \mathrm{S}))$ were 267 determined with the following Eq.(5, 6) (Wang et al. 2012):

$$
\mathrm{RTInK}_{d}=\frac{\triangle \mathrm{S}}{R}-\frac{\triangle \mathrm{H}}{R T}
$$


As shown in table $S 3$, the positive $\Delta H$ values and the negative $\Delta G$ indicated the sorption process is endothermic and spontaneous. The phenomenon can be attributed to the following two reasons: 1) the deprotonation of surface phosphate group would occur with the increasing temperature, which enhances

273 the affinity of t-DOPOR toward $\mathrm{U}(\mathrm{VI})$; 2) higher temperature is conducive to $\mathrm{U}(\mathrm{VI})$ ion migrated to the surface of t-DOPOR in solution (Malamis and Katsou 2013). Besides, the $\triangle \mathrm{G}$ value become more negative with the increasing temperature, implying the sorption easily occurs in high temperature.

The effect of ionic strength

The adsorption trend at various ionic strengths can be used to identify the potential adsorption mechanisms (Wang et al. 2016). The adsorption behavior of U(VI) by t-DOPOR was investigated at various ionic strengths (i.e., $0.1,1,10,100,1000 \mathrm{mmol} / \mathrm{L}$ ). With the ionic strength increasing from 0.1 demonstrated by previous study, the adsorption trend is very sensitive to ionic strength when $\mathrm{U}(\mathrm{VI})$

283 adsorbed by cation exchange and/or outer-sphere complexation, conversely, the adsorption trend is not 284 affecting when U(VI) adsorbed by the inner-sphere complexation (Sun et al. 2017). Herein, the ignorable effect of ionic strength implied that the interaction of U(VI) and t-DOPOR can be elucidated as an innersphere complexation. In addition, the results revealed that t-DOPOR could remove U(VI) from highly saline low level radioactive effluents (Yin et al. 2021).

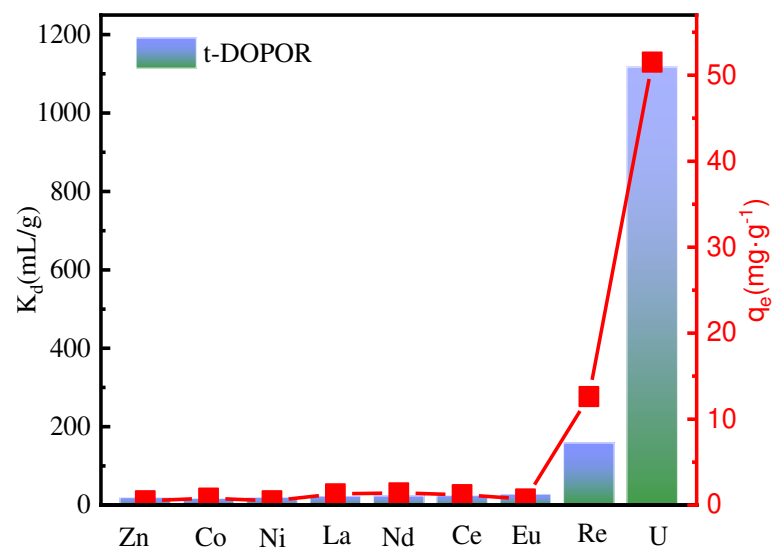


Fig. 4 Effect of co-existing metal ions on the adsorption of U(VI) by t-DOPOR $\left(\mathrm{C}_{0}=0.5 \mathrm{mmol}\right.$

$$
\mathrm{L}^{-1}, \mathrm{pH}=3, \mathrm{~m} / \mathrm{v}=1 \mathrm{~g} / \mathrm{L} \text { ), (a) } \mathrm{K}_{\mathrm{d}} \text { and } \mathrm{q}_{\mathrm{e}} \text { of metal ions }
$$

The synthesized adsorbent should have satisfying selectivity toward capturing U(VI) from competing ions in practical application. To evaluated the selectivity of t-DOPOR toward $\mathrm{U}(\mathrm{VI})$ from the practical point of view, simulated radioactive wastewater containing a range of metal ions, such as $\mathrm{Ce}(\mathrm{III})$, $\mathrm{Zn}(\mathrm{II}), \mathrm{Co}(\mathrm{II}), \mathrm{Ni}(\mathrm{II}), \mathrm{Yb}(\mathrm{III}), \mathrm{Nd}(\mathrm{III}), \mathrm{Eu}(\mathrm{III})$ and $\mathrm{La}(\mathrm{III})$, was prepared. As shown in Fig. 4, the adsorption capacity of $\mathrm{U}(\mathrm{VI})$ in the presence of competitive ions was $51.51 \mathrm{mg} / \mathrm{g}$. Also noteworthy is that the remarkable high value of $\mathrm{K}_{d}^{\mathrm{U}}$ of t-DOPOR was around 1200 than the value of $\mathrm{K}_{\mathrm{d}}$ of other coexisting ions, indicating t-DOPOR holds an excellent affinity for $\mathrm{U}(\mathrm{VI})$. This performance is superior to those of reported GO-CS (Huang et al. 2017), PEI- rGO/MoS 2 CAs-3 (Guo et al. 2020) and FH/GO (Li et al. 2018). Clearly, t-DOPOR enable highly selective U(VI) adsorption over multi-component system that major content in radioactive wastewater.

\section{Separation experiments in the binary system}

305 The effect of $\mathrm{pH}$

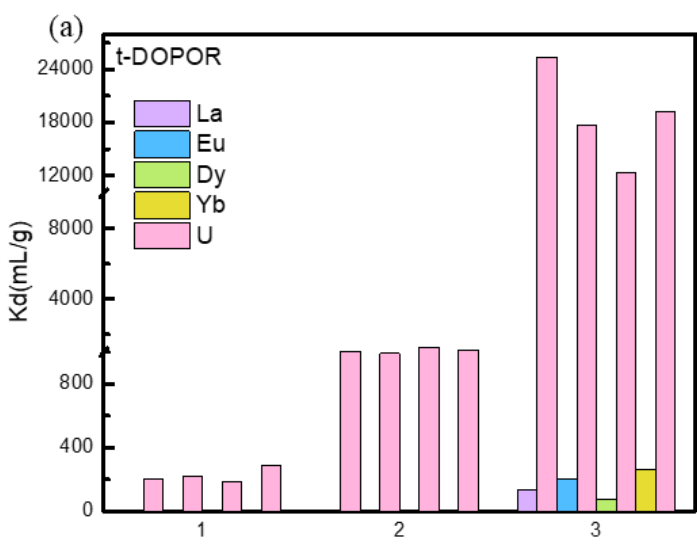

$\mathrm{pH}$

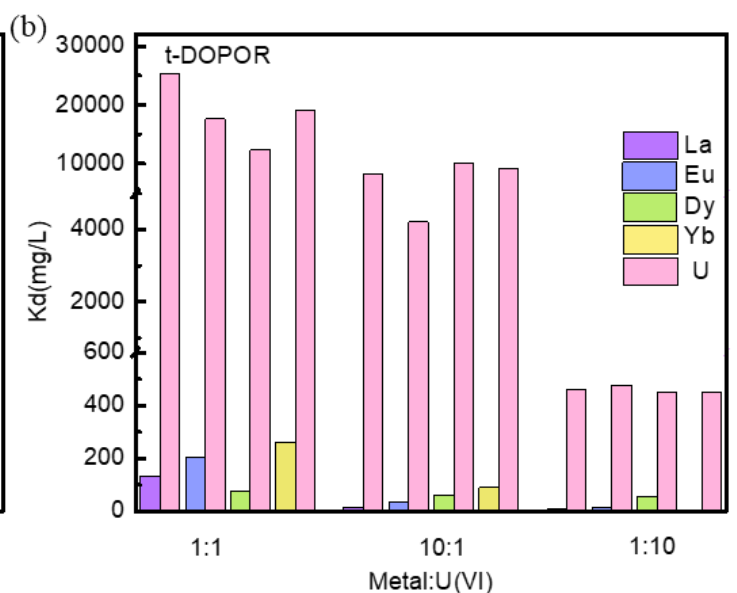

Metal:U(VI)

Fig. 5 (a) Distribution coefficient $\left(\mathrm{K}_{\mathrm{d}}\right)$ for uranium and other metals on t-DOPOR in U-La, U-Eu,

U-Dy, U-Yb binary system in $\mathrm{pH} 1-3\left(\mathrm{C}_{0}=0.1 \mathrm{mmol} \mathrm{L}^{-1}\right.$ for all metal ions, $\left.\mathrm{m} / \mathrm{v}=1 \mathrm{~g} / \mathrm{L}\right)$; (b) Effect of different ratio of composition vs \% removal efficiencies in U-La, U-Eu, U-Dy, U-Yb binary system

$$
(\mathrm{pH} 3, \mathrm{~m} / \mathrm{v}=1 \mathrm{~g} / \mathrm{L})
$$

311 The separation of actinides from lanthanides is an important challenge for the processing of 312 radioactive water. Herein, the effect of lanthanides ions on t-DOPOR for U(VI) adsorption in the binary 
313 system was investigated at various $\mathrm{pH}$. Among the experiment, $\mathrm{La}^{3+}$ was the representative of light 314 lanthanides, $\mathrm{Eu}^{3+}, \mathrm{Dy}^{3+}$ were the representatives of middle lanthanides, and $\mathrm{Yb}^{3+}$ was the representatives 315 of heavy lanthanides. As shown in Fig. 5, t-DOPOR could efficiently adsorb U(VI) ions and rarely adsorb 316 other lanthanide ions ( $\mathrm{La}(\mathrm{III}), \mathrm{Eu}(\mathrm{III}), \mathrm{Dy}(\mathrm{III}), \mathrm{Yb}(\mathrm{III}))$ when $\mathrm{pH}<3$. As shown in Fig. 5a, at $\mathrm{pH}=3$, a 317 large distribution coefficient, $\mathrm{K}_{\mathrm{d}}^{\mathrm{U}}$, exceed $1.4 \times 10^{4} \mathrm{mg} / \mathrm{g}$ and even up to $2.54 \times 10^{4}$, while the 318 corresponding values for other earth elements were below $205 \mathrm{mg} / \mathrm{g}$. Consequently, the values of $\mathrm{SF}_{\mathrm{U} / \mathrm{La}}$, $319 \mathrm{SF}_{\mathrm{U} / \mathrm{Eu}}, \mathrm{SF}_{\mathrm{U} / \mathrm{Dy}}$, and $\mathrm{SF}_{\mathrm{U} / \mathrm{Yb}}$, are $192.30,86.04,161.17$, and 73.42, respectively (see Table 1).

Table1 Separation factors (SF) of U(VI) and other metal ions (M) at different $\mathrm{pH}$

\begin{tabular}{ccccc}
\hline & \multicolumn{4}{c}{$\mathrm{SF}_{\mathrm{U} / \mathrm{M}}$} \\
\cline { 2 - 5 } $\mathrm{pH}$ & $\mathrm{U} / \mathrm{La}$ & $\mathrm{U} / \mathrm{Eu}$ & $\mathrm{U} / \mathrm{Dy}$ & $\mathrm{U} / \mathrm{Yb}$ \\
\hline 1 & 25.71 & 172.40 & 297.65 & 408.66 \\
2 & 180.39 & 1543.93 & 154.06 & 261.31 \\
3 & 192.30 & 86.04 & 161.17 & 73.42 \\
\hline
\end{tabular}

322 The effect of different ratio of composition

323 The concentration of ions is variable in the practical industrial. Thus, the effect of different ratio of 324 composition in binary system was studied at $\mathrm{pH} 3$ on adsorption of $\mathrm{U}(\mathrm{VI})$. As shown in Fig. 5b, when 325 the $\mathrm{U}(\mathrm{VI})$ concentration was lower $\left(0.1 \mathrm{mmol} \mathrm{L}^{-1}\right.$ in $10: 1$ ratio), the $\mathrm{Kd}$ of $\mathrm{U}(\mathrm{VI})$ exceeded $4.0 \times 10^{3} \mathrm{mg} / \mathrm{g}$, 326 while the $\mathrm{K}_{\mathrm{d}}$ of other lanthanides ions ( $\mathrm{La}(\mathrm{III})$, Eu(III), Dy(III), $\mathrm{Yb}(\mathrm{III})$ ) were below $100 \mathrm{mg} / \mathrm{g}$. In the 327 high $\mathrm{U}(\mathrm{VI})$ concentration ( $1 \mathrm{mmol} \mathrm{L}^{-1}$ in 1:10 ratio), the $\mathrm{Kd}^{\mathrm{U}}$ exceeded $450 \mathrm{mg} / \mathrm{g}$, while the $\mathrm{Kd}^{\mathrm{Ln}}$ were 328 below $55 \mathrm{mg} / \mathrm{g}$. Thus, t-DOPOR exhibited attractive U/Ln separation factors of SF U/Ln (Table 2).

329 In summary, t-DOPOR can yield good separation of U(VI) from other lanthanides ions, suggesting 330 that $\mathrm{t}$-DOPOR could be used as potential adsorbent in separation of actinides ions from lanthanides ions 331 in the practical industrial.

332 Table 2 Separation factors (Sf) of U(VI) and other metal ions (M) at different concentrations

\begin{tabular}{|c|c|c|c|c|}
\hline \multirow[b]{2}{*}{$C(U): C(\operatorname{Ln})$} & \multicolumn{4}{|c|}{$\mathrm{SF}_{\mathrm{U} / \mathrm{M}}$} \\
\hline & $\mathrm{U} / \mathrm{La}$ & $\mathrm{U} / \mathrm{Eu}$ & U/Dy & $\mathrm{U} / \mathrm{Yb}$ \\
\hline $1: 1$ & 192.30 & 86.04 & 161.17 & 73.42 \\
\hline
\end{tabular}




$\begin{array}{lllll}10: 1 & 497.28 & 123.52 & 168.20 & 231.30 \\ 1: 10 & 64.48 & 36.27 & 8.35 & 74.55\end{array}$

\section{Regeneration study}

The service life of adsorbent is important as it greatly affected the treatment cost from the practical point of view. The consecutive adsorption-desorption cycles were repeated five times using $0.1 \mathrm{M} \mathrm{HCl}$ used as eluting reagent. As presented in Fig. 1e, the adsorption efficiency slightly decreased from $\sim 97 \%$ to $\sim 80 \%$ after five desorption-desorption cycles. It was noted that the adsorption efficiency of t-DOPOR t-DOPOR possesses good stability and reusability.

\section{Dynamic column and the trace amount of U(VI) experiment}

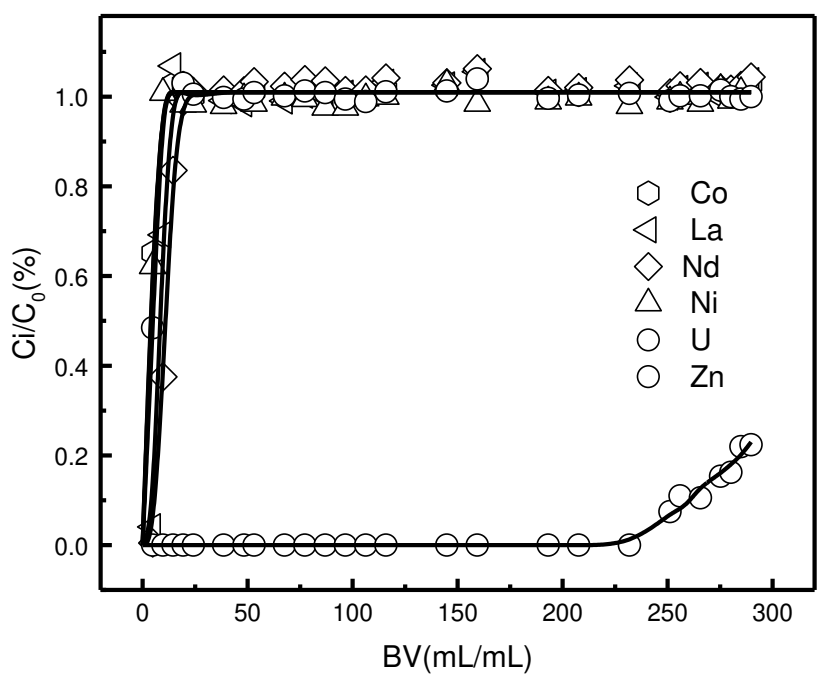

Fig. 6 The process of fixed-bed column experiments and (b) breakthrough curves of U(VI) selective adsorption on t-DOPOR at $\mathrm{pH}=3, \mathrm{~T}=293 \mathrm{~K}, \mathrm{~m}(\mathrm{t}-\mathrm{DOPOR})=0.4 \mathrm{~g}, \mathrm{C}_{0(\mathrm{M})}=1 \mathrm{mmol} / \mathrm{L}, \mathrm{C}_{0(\mathrm{U})}=0.1 \mathrm{mmol} / \mathrm{L}$,

$$
\mathrm{V}=19.32 \mathrm{~mL} / \mathrm{h} .
$$

The dynamic column experiment of $\mathrm{U}(\mathrm{VI})$ and other competing ions ( $\mathrm{Zn}(\mathrm{II}), \mathrm{Co}(\mathrm{II}), \mathrm{Ni}(\mathrm{II}), \mathrm{Nd}(\mathrm{III})$,

$348 \mathrm{La}(\mathrm{IiI}))$ was explored, which can give theoretical and technical advice to increase the usage of t-DOPOR

349 on the large-scale application. As shown in Fig. 6, the breakthrough point (defined as $\mathrm{Ci} / \mathrm{Co} \leq 5 \%$ ) of $350 \mathrm{Zn}(\mathrm{II}), \mathrm{Co}(\mathrm{II}), \mathrm{Ni}(\mathrm{II}), \mathrm{Nd}(\mathrm{III}), \mathrm{La}(\mathrm{III})$ took place at the beginning and reached complete saturation at around $15 \mathrm{BV}$. It can be seen that the value of $\mathrm{Ci} / \mathrm{Co}$ of $\mathrm{U}(\mathrm{VI})$ on $\mathrm{t}-\mathrm{DOPOR}$ remained below $5 \%$ at $\mathrm{BV}<$ 
$251 \mathrm{~mL} / \mathrm{mL}$, which was significantly higher than that of competing metal ions, which suggests the considerable selectivity of t-DOPOR for U(VI) in the presence of competing metal ions.

In addition, given the uranium contamination in groundwater caused by the improper treatment of uranium tailings is a serious problem, the simulated groundwater was prepared to check the removal performance of t-DOPOR under the environmentally relevant conditions. As shown in table S4, tDOPOR could remove $\sim 98.5 \%$ of the $6.37 \mathrm{ug} / \mathrm{L} \mathrm{U}(\mathrm{VI})$ from contaminated pure water, and remove $\sim 99.8 \%$ of the $24.3 \mathrm{ug} / \mathrm{L} \mathrm{U}(\mathrm{VI})$ from simulated groundwater. This result demonstrated t-DOPOR is capable of effectively removing U(VI) from the contaminated groundwater at trace levels.

\section{FTIR analysis}

After adsorption U(VI), as shown in Fig. S1, a new peak appeared at $925 \mathrm{~cm}^{-1}$ which was assigned to the antisymmetric vibration of the $\mathrm{UO}_{2}{ }^{2+}$ (Szlachta et al. 2020). The peak of $-\mathrm{NH}\left(\sim 1577 \mathrm{~cm}^{-1}\right)$, the $\mathrm{N}-\mathrm{H}$ deformation vibration at $1569 \mathrm{~cm}^{-1}$ in t-DOPOR is replaced by two absorption peaks at 1544 and $1572 \mathrm{~cm}^{-1}$, which related to the protonation and hydration of amino group on the surface of t-DOPOR (Cai et al. 2020). Besides, the peak of $\mathrm{P}=\mathrm{O}$ shifted from $1243 \mathrm{~cm}^{-1}$ to $1253 \mathrm{~cm}^{-1}$. Accordingly, the $\mathrm{P}=\mathrm{O}$ and $\mathrm{N}-\mathrm{H}$ group were contributed to the adsorption of $\mathrm{U}(\mathrm{VI})$.

\section{XPS analysis}

The XPS analysis was adopted to further investigate the adsorption mechanism between t-DOPOR and $\mathrm{U}(\mathrm{VI})$. After the adsorption of $\mathrm{U}(\mathrm{VI})$, a strong double $\mathrm{U} 4 \mathrm{f}$ peaks was appeared in the spectrum of $\mathrm{t}$ DOPOR (Fig. 7a), indicating the U(VI) adsorbed by t-DOPOR. The U 4f peak could be resolved into

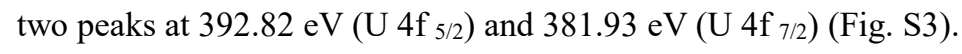

The fitting of $\mathrm{P} 2 \mathrm{p}$ and $\mathrm{O}$ 1s, $\mathrm{N}$ 1s spectra could deduce the specific functional group that coordinated with U(VI). The high-resolution P 2p spectrum (Fig. 7b) was decomposed into two peaks at 133.04, 132.20 eV, which are assigned to $P 2 p_{1 / 2}$ and $P 2 p_{3 / 2}$, respectively. The peaks of $P 2 p_{1 / 2}$ and $P 2 p_{3 / 2}$ were shifted to a higher energy after U(VI) uptake, suggesting that the P-related functional group plays a crucial role in the capture of $\mathrm{U}(\mathrm{VI})$. The concrete phosphorus group involved can be deduced by $\mathrm{O} 1 \mathrm{~s}$ spectra. As shown in Fig 7c, the high-resolution $\mathrm{O}$ 1s spectrum was well fitted into four peaks, $\mathrm{C}=\mathrm{O}$, 

uptake. Specifically, the binding energy of $\mathrm{P}=\mathrm{O}, \mathrm{C}=\mathrm{O}$, and $-\mathrm{OH}$ bonds were shifted higher values. In 383 contrast, the peak position of C-O-P changed slightly after U(VI) uptake. These phenomena indicated 384 that the adsorption is primarily attributed to $\mathrm{U}(\mathrm{VI})$ coordinated with $\mathrm{P}=\mathrm{O}$ rather than the C-O-P. Similarly, the high-resolution N 1s spectrum (Fig. 7d) was resolved into two peaks 399.58, 399.11eV, corresponding to $\mathrm{NH}, \mathrm{NH}_{2}{ }^{+}$(Park et al. 2010), respectively. After U(VI) adsorption, the position of $\mathrm{NH}$ was shifted

387 (about $0.63 \mathrm{eV}$ ) to higher energy, implying that the lone pair of electrons on the $\mathrm{N}$ atom of $\mathrm{NH}$ group was 388 shared with the $\mathrm{U}(\mathrm{VI})$. These results suggested that the adsorption of $\mathrm{U}(\mathrm{VI})$ is mainly induced by innersphere surface complexation between $\mathrm{U}(\mathrm{VI})$ and $-\mathrm{OH}$, $-\mathrm{NH}$ and $\mathrm{P}=\mathrm{O}$ groups of the t-DOPOR and 390 electrostatic interaction and as depicted in Fig. 8.
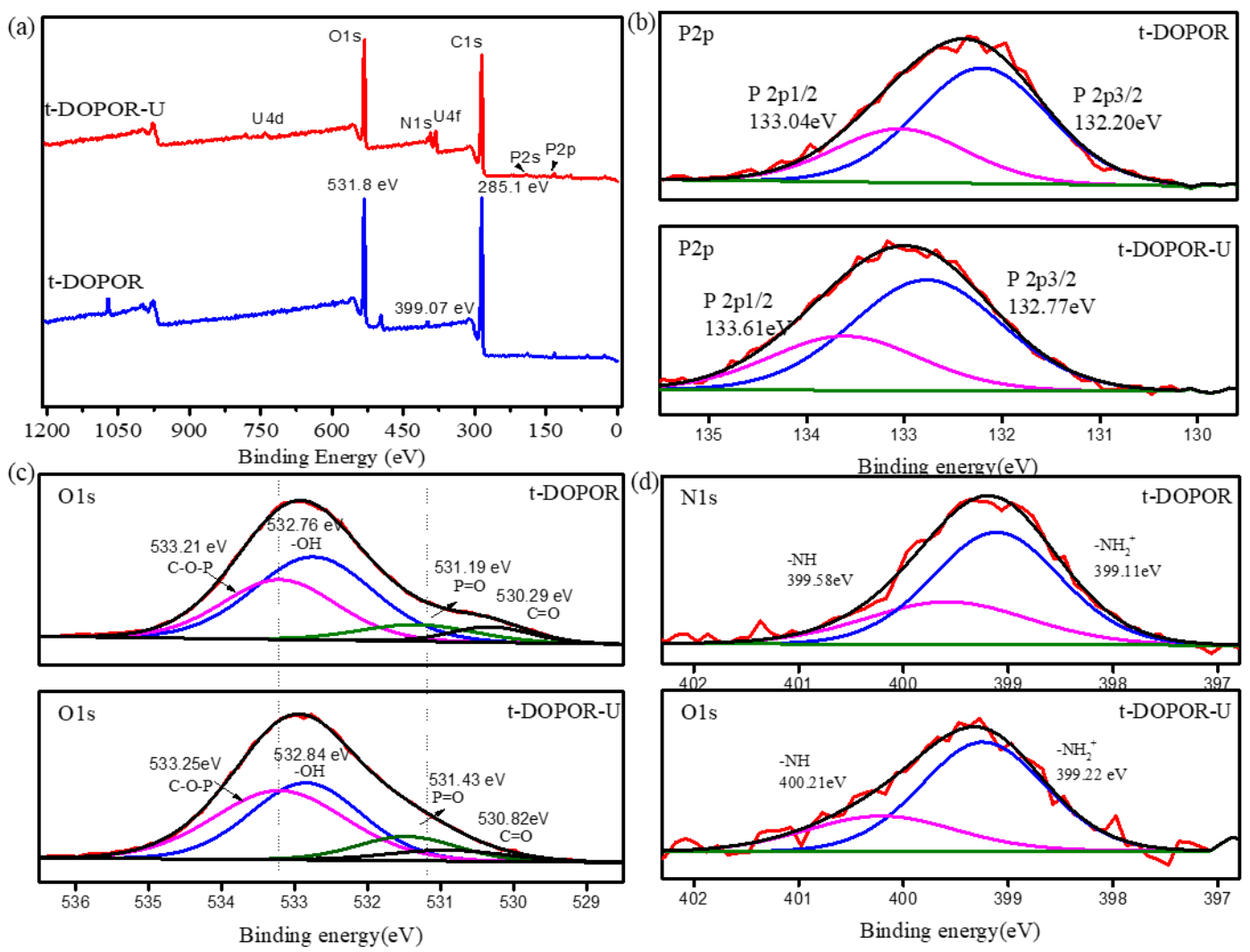

Fig. 7 (a) XPS survey scans of t-DOPOR before and after U(VI) uptake (b) high resolution scans

393 of P $2 p$ spectra before and after (c) high resolution scans of O 1s spectra before and after. (d) high resolution scans of $\mathrm{N} 1$ s spectra before and after $\mathrm{U}(\mathrm{VI})$ uptake. 


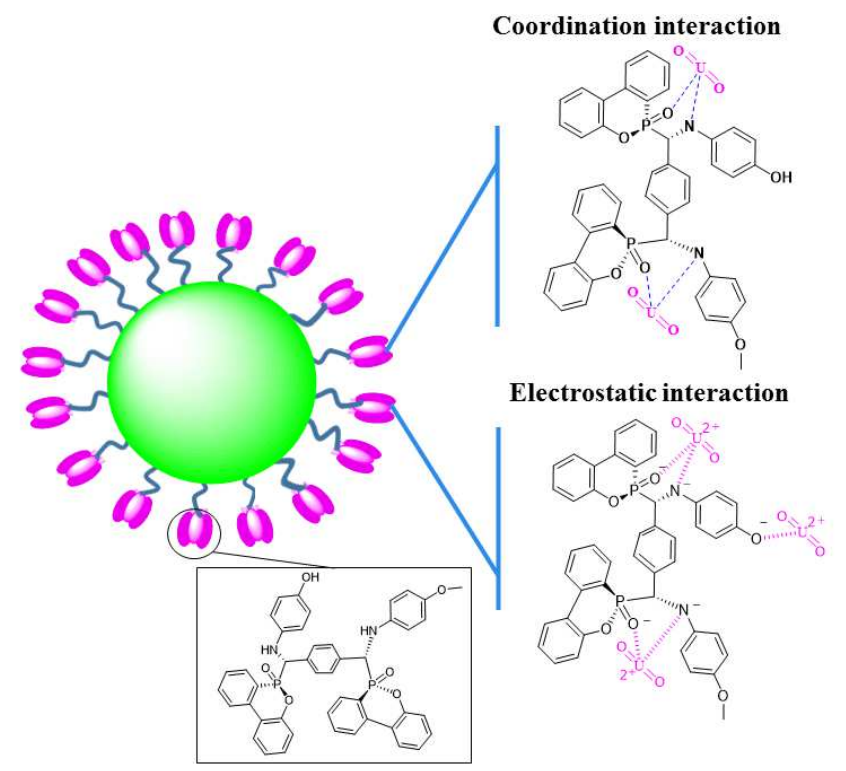

Fig. 8 Possible adsorption mechanism between t-DOPOR and U(VI)

\section{Conclusions}

In this work, a novel t-DOPOR was prepared via radiation technology to selectively separate $\mathrm{U}(\mathrm{VI})$ from acidic solution. As the chosen functionalized monomer, t-DOPO with abundant functional group, such as $-\mathrm{OH}$, $-\mathrm{NH}$ and $\mathrm{P}=\mathrm{O}$, which have strong affinity to $\mathrm{U}(\mathrm{VI})$. Characterization of the t-DOPOR through different techniques confirmed that t-DOPO is successfully modified on cellulose, and the 403 introduction of t-DOPO endows the cellulose with chemical stability and rich functional group. The tDOPOR possesses a notable affinity and selectivity toward U(VI) over other lanthanides and heavy metal ions under acidic conditions from simulated radioactive wastewater, especially due to the strong synergistic effect of cellulose and t-DOPO. The U(VI) sorption process on t-DOPOR accorded with the Langmuir isotherm model and pseudo-second-order kinetic model, revealing a monolayer chemisorption. Besides, t-DOPOR exhibited good recyclability and highly salt resistant. Finally, the adsorption and

409 favorable selectivity of t-DOPOR toward U(VI) were attributed to the inner-sphere surface complexation

410 between $\mathrm{U}(\mathrm{VI})$ and surface-grated $-\mathrm{OH},-\mathrm{NH}$ and $\mathrm{P}=\mathrm{O}$ groups. Notably, t-DOPOR could separate 411 selectively $\mathrm{U}(\mathrm{VI})$ in column experiment, and efficiently remove the trace amount of $\mathrm{U}(\mathrm{VI})$ from 412 simulated groundwater, which is expected to apply to the separation and remediation of U(VI) from 413 actual environment. The experiment finding also indicated DOPO derivative could use as a novel class 414 of suitable ligand for removal of $\mathrm{U}(\mathrm{VI})$ from aqueous solution and pave the way for the further 415 application of DOPO in adsorption field. 
This work was supported by a grant from the nuclear energy development project titled as technology for the mining and metallurgy of associated uranium resources-on the demonstration of uranium co-mining in Bayan Ura (Inner Mongolia) of state administration of science, Technology and Industry for National Defense, PRC. The authors would like to thank the Analysis and testing center of Huazhong University of Science and Technology.

\section{Compliance with ethical standards}

\section{Conflict of interest}

The authors declare that they have no conflicts of interest.

\section{Human or animal rights}

This article does not contain any studies with human participants or animals performed by any of the authors.

\section{Informed consent}

Informed consent was obtained from all individual participants included in the study.

\section{References}

433 Ai Y, Liu Y, Lan W, et al (2018) The effect of pH on the U (VI) sorption on graphene oxide (GO): A 434 theoretical study. Chem Eng J 343:460-466. https://doi.org/10.1016/j.cej.2018.03.027

435 Bai Z, Song L, Hu Y, Yuen RKK (2013) Preparation, flame retardancy, and thermal degradation of unsaturated polyester resin modified with a novel phosphorus containing acrylate. Ind Eng Chem Res

437 52:12855-12864. https://doi.org/10.1021/ie401662x

438 Beltrami D, Chagnes A, Haddad M, et al (2014) Solvent extraction studies of uranium(VI) from 439 phosphoric acid: Role of synergistic reagents in mixture with bis(2-ethylhexyl) phosphoric acid. 440 Hydrometallurgy 144-145:207-214. https://doi.org/10.1016/j.hydromet.2014.02.010

441 Budnyak TM, Strizhak A V., Gładysz-Płaska A, et al (2016) Silica with immobilized phosphinic acid442 derivative for uranium extraction. J Hazard Mater 314:326-340. 443 https://doi.org/10.1016/j.jhazmat.2016.04.056 
444 Cai C, Wang R, Liu S, et al (2020) Synthesis of self-assembled phytic acid-MXene nanocomposites via 445 a facile hydrothermal approach with elevated dye adsorption capacities. Colloids Surfaces A 446 Physicochem Eng Asp 589:124468. https://doi.org/10.1016/j.colsurfa.2020.124468

447 Cai Y, Chen L, Yang S, et al (2019) Rational Synthesis of Novel Phosphorylated Chitosan448 Carboxymethyl Cellulose Composite for Highly Effective Decontamination of U(VI). ACS Sustain 449 Chem Eng 7:5393-5403. https://doi.org/10.1021/acssuschemeng.8b06416

450 Cai Y, Wu C, Liu Z, et al (2017) Fabrication of a phosphorylated graphene oxide-chitosan composite 451 for highly effective and selective capture of U(VI). Environ Sci Nano 4:1876-1886. 452 https://doi.org/10.1039/c7en00412e

453 Cao J, Fei D, Tian X, et al (2017) Novel modified microcrystalline cellulose-based porous material for 454 fast and effective heavy-metal removal from aqueous solution. Cellulose 24:5565-5577. 455 https://doi.org/10.1007/s10570-017-1504-6

456 Chang Y, Chen D (2006) Recovery of gold(III) ions by a chitosancoated magnetic nano-adsorbent. Gold 457 Bull 39:98-102. https://doi.org/10.1007/BF03215536

458 Chen L, Yin X, Yu Q, et al (2019) Rapid and selective capture of perrhenate anion from simulated 459 groundwater by a mesoporous silica-supported anion exchanger. Microporous Mesoporous Mater $460 \quad 274: 155-162$. https://doi.org/10.1016/j.micromeso.2018.07.029

461 Chen Y, Zhu B, Wu D, et al (2012) Eu(III) adsorption using di(2-thylhexly) phosphoric acid-immobilized 462 magnetic GMZ bentonite. Chem Eng J 181-182:387-396. https://doi.org/10.1016/j.cej.2011.11.100

463 Cheng W, Ding C, Wang X, et al (2016) Competitive sorption of $\mathrm{As}(\mathrm{V})$ and $\mathrm{Cr}(\mathrm{VI})$ on carbonaceous 464 nanofibers. Chem Eng J 293:311-318. https://doi.org/10.1016/j.cej.2016.02.073

465 Dartiguelongue A, Chagnes A, Provost E, et al (2016) Modelling of uranium(VI) extraction by 466 D2EHPA/TOPO from phosphoric acid within a wide range of concentrations. Hydrometallurgy 165:57467 63. https://doi.org/10.1016/j.hydromet.2015.11.007

468 Ding C, Cheng W, Sun Y, Wang X (2015) Effects of Bacillus subtilis on the reduction of U(VI) by nano$469 \quad \mathrm{Fe}^{0}$. Geochim Cosmochim Acta 165:86-107. https://doi.org/10.1016/j.gca.2015.05.036

470 Dong Z, Zhao L (2018) Surface modification of cellulose microsphere with imidazolium-based ionic 471 liquid as adsorbent: effect of anion variation on adsorption ability towards $\mathrm{Au}(\mathrm{III})$. Cellulose 25:2205- 
473 Fiol N, Villaescusa I (2009) Determination of sorbent point zero charge: Usefulness in sorption studies.

474 Environ Chem Lett 7:79-84. https://doi.org/10.1007/s10311-008-0139-0

475 Guo D, Song X, Zhang L, et al (2020) Recovery of uranium (VI) from aqueous solutions by the 476 polyethyleneimine-functionalized reduced graphene oxide/molybdenum disulfide composition aerogels.

477 J Taiwan Inst Chem Eng 106:198-205. https://doi.org/10.1016/j.jtice.2019.09.029

478 Guo H, Zhang Z, Hojo H, et al (2019) Catalytic Removal of Benzene at Mild Temperature over 479 Manganese Oxide Catalysts. Catal Surv from Asia 23:199-209. https://doi.org/10.1007/s10563-019$480 \quad 09268-2$

481 Hokkanen S, Bhatnagar A, Sillanpää M (2016) A review on modification methods to cellulose-based 482 adsorbents to improve adsorption capacity. Water Res 91:156-173. 483 https://doi.org/10.1016/j.watres.2016.01.008

484 Huang Z, Li Z, Zheng L, et al (2017) Interaction mechanism of uranium(VI) with three-dimensional 485 graphene oxide-chitosan composite: Insights from batch experiments, IR, XPS, and EXAFS 486 spectroscopy. Chem Eng J 328:1066-1074. https://doi.org/10.1016/j.cej.2017.07.067

487 Huang ZW, Li ZJ, Wu QY, et al (2018) Simultaneous elimination of cationic uranium(VI) and anionic 488 rhenium(VII) by graphene oxide-poly(ethyleneimine) macrostructures: A batch, XPS, EXAFS, and DFT 489 combined study. Environ Sci Nano 5:2077-2087. https://doi.org/10.1039/c8en00677f

490 Li R, Zhao H, Liu C, et al (2017) The recovery of uranium from irradiated thorium by extraction with 491 di-1-methyl heptyl methylphosphonate (DMHMP)/n-dodecane. Sep Purif Technol 188:219-227. 492 https://doi.org/10.1016/j.seppur.2017.07.038

493 Li Y, Zou G, Yang S, et al (2018) Bioassembly of fungal hyphae/graphene oxide composite as high 494 performance adsorbents for U(VI) removal. Appl Surf Sci 458:226-235. 495 https://doi.org/10.1016/j.apsusc.2018.07.081

496 Lv M, Yan L, Liu C, et al (2018) Non-covalent functionalized graphene oxide (GO) adsorbent with an 497 organic gelator for co-adsorption of dye, endocrine-disruptor, pharmaceutical and metal ion. Chem Eng 498 J 349:791-799. https://doi.org/10.1016/j.cej.2018.04.153

499 Malamis S, Katsou E (2013) A review on zinc and nickel adsorption on natural and modified zeolite, 
Mellah A, Chegrouche S, Barkat M (2007) The precipitation of ammonium uranyl carbonate (AUC):

503 Thermodynamic and kinetic investigations. Hydrometallurgy 85:163-171.

504 https://doi.org/10.1016/j.hydromet.2006.08.011

505 Misra N, Goel NK, Shelkar SA, et al (2016) Catalase immobilized-radiation grafted functional cellulose

506 matrix: A novel biocatalytic system. J Mol Catal B Enzym 133:S172-S178.

507 https://doi.org/10.1016/j.molcatb.2017.01.001

508 Pan N, Jin Y, Wang X, et al (2019) A Self-Assembled Supramolecular Material Containing Phosphoric 509 Acid for Ultrafast and Efficient Capture of Uranium from Acidic Solutions. ACS Sustain Chem Eng 510 7:950-960. https://doi.org/10.1021/acssuschemeng.8b04596

511 Park J, Won SW, Mao J, et al (2010) Recovery of Pd(II) from hydrochloric solution using polyallylamine 512 hydrochloride-modified Escherichia coli biomass. J Hazard Mater 181:794-800. 513 https://doi.org/10.1016/j.jhazmat.2010.05.083

514 Satilmis B, Isık T, Demir MM, Uyar T (2019) Amidoxime functionalized Polymers of Intrinsic 515 Microporosity (PIM-1) electrospun ultrafine fibers for rapid removal of uranyl ions from water. Appl 516 Surf Sci 467-468:648-657. https://doi.org/10.1016/j.apsusc.2018.10.210

517 Shao D, Wang X, Ren X, et al (2018) Polyamidoxime functionalized with phosphate groups by plasma 518 technique for effective $\mathrm{U}(\mathrm{VI})$ adsorption. $\mathrm{J}$ Ind Eng Chem 67:380-387. 519 https://doi.org/10.1016/j.jiec.2018.07.012

520 Sun Y, Wang X, Lu S, et al (2017) Plasma-Facilitated Synthesis of Amidoxime/Carbon Nanofiber 521 Hybrids for Effective Enrichment of 238U(VI) and 241Am(III). Environ Sci Technol 51:12274-12282. 522 https://doi.org/10.1021/acs.est.7b02745

523 Szlachta M, Neitola R, Peräniemi S, Vepsäläinen J (2020) Effective separation of uranium from mine 524 process effluents using chitosan as a recyclable natural adsorbent. Sep Purif Technol 253:1-11. 525 https://doi.org/10.1016/j.seppur.2020.117493

526 Wang H, Ma L, Cao K, et al (2012) Selective solid-phase extraction of uranium by salicylideneimine527 functionalized hydrothermal carbon. J Hazard Mater 229-230:321-330. 
529 Wang T, Xu M, Han X, et al (2019) Petroleum pitch-based porous aromatic frameworks with phosphonate ligand for efficient separation of uranium from radioactive effluents. J Hazard Mater

531 368:214-220. https://doi.org/https://doi.org/10.1016/j.jhazmat.2019.01.048

532 Wang X, Fan Q, Yu S, et al (2016) High sorption of U(VI) on graphene oxides studied by batch 533 experimental and theoretical calculations. Chem. Eng. J. 287:448-455

534 Wendels S, Chavez T, Bonnet M, et al (2017) Recent developments in organophosphorus flame 535 retardants containing P-C bond and their applications. Materials (Basel) 10:. 536 https://doi.org/10.3390/ma10070784

537 Xiao D, Ding W, Zhang J, et al (2019) Fabrication of a versatile lignin-based nano-trap for heavy metal 538 ion capture and bacterial inhibition. Chem Eng J 358:310-320. https://doi.org/10.1016/j.cej.2018.10.037

539 Xie C, Zhou WR, Zhang GX (2018) Room-temperature synthesis of two kinds of DOPO-based curing 540 agents and properties of flame retardant epoxy resins. Sci Technol Eng 18:1671-1815. $541 \quad$ https://doi.org/10.3969/j.issn.1671-1815.2018.16.038

542 Yin J, Yang S, He W, et al (2021) Biogene-derived aerogels for simultaneously selective adsorption of 543 uranium(VI) and strontium(II) by co-imprinting method. Sep Purif Technol 271:118849. 544 https://doi.org/10.1016/j.seppur.2021.118849

545 Yuan D, Zhang S, Tan J, et al (2020) Highly efficacious entrapment of Th (IV) and U (VI) from rare 546 earth elements in concentrated nitric acid solution using a phosphonic acid functionalized porous organic 547 polymer adsorbent. Sep Purif Technol 237:116379. https://doi.org/10.1016/j.seppur.2019.116379

548 Yuan F, Wu C, Cai Y, et al (2017) Synthesis of phytic acid-decorated titanate nanotubes for high efficient 549 and high selective removal of $\mathrm{U}(\mathrm{VI})$. Chem Eng J 322:353-365. 550 https://doi.org/10.1016/j.cej.2017.03.156

551 Zhang F, Ma KQ, Li Y, et al (2020) Selective separation of thorium from rare earths and uranium in 552 acidic solutions by phosphorodiamidate-functionalized silica. Chem Eng J 392:. 553 https://doi.org/10.1016/j.cej.2019.123717

554 Zheng R, Bao S, Zhang Y, Chen B (2018) Synthesis of Di-(2-ethylhexyl) Phosphoric Acid (D2EHPA)555 Tributyl Phosphate (TBP) Impregnated Resin and Application in Adsorption of Vanadium(IV). Minerals 
556 8:. https://doi.org/10.3390/min8050206

557 Zhu J, Liu Q, Li Z, et al (2018) Efficient extraction of uranium from aqueous solution using an amino-

558 functionalized magnetic titanate nanotubes. J Hazard Mater 353:9-17.

559 https://doi.org/10.1016/j.jhazmat.2018.03.042

560 


\section{Supplementary Files}

This is a list of supplementary files associated with this preprint. Click to download.

- supplementarymaterialDOPO.docx 